\title{
PERLINDUNGAN HUKUM TERHADAP MAHASISWA PENDIDIKAN NERS DI INSTITUSI KESEHATAN
}

\author{
LEGAL PROTECTION FOR PROFESION NURSING STUDENT AT HEALTH INSTITUTION
}

\author{
Masta Haro \\ Fakultas IImu Keperawatan, Universitas Klabat \\ Email: mastatambunan01@gmail.com
}

\begin{abstract}
ABSTRAK
Pendahuluan: Tahap pendidikan Keperawatan tahap profesi (Ners) sepenuhnya dilakukan di institusi pelayanan kesehatan, namun fakta menunjukkan belum ada Rumah Sakit Pendidikan (RSP) Keperawatan dan Peraturan Pemerintah yang mengatur tentang perlindungan kepada mahasiswa profesi ners termasuk hak dan kewajiban mahasiswa profesi ners belum ada. Tujuan: penelitian ini untuk mengetahui perlindungan hukum terhadap mahasiswa pendidikan Ners dalam melaksanakan praktik klinis di institusi pelayanan kesehatan. Metode: Metode penelitian ini adalah pendekatan yuridis normatif, yaitu penelitian hukum yang dilakukan dengan cara meneliti data atau bahan perpustakaan yang merupakan data sekunder berupa bahan hukum primer, bahan hukum sekunder maupun bahan hukum tersier. Hasil: Penelitian ini mengindikasikan bahwa belum adanya kejelasan hukum dan aturan yang kongkrit yang memberikan perlindungan kepada mahasiswa profesi ners dalam melaksanakan praktik klinisnya. Diskusi: Diharapkan agar pemerintah membuat peraturan yang jelas sebagai perlindungan hukum bagi mahasiswa pendidikan Ners dalam melakasanakan praktik klinis, mendorong Rumah Sakit Pendidikan Perawat, institusi pendidikan Ners mempersiapkan mahasiswa secara optimal, Institusi Kesehatan mempersiapkan pembimbing lapangan secara optimal, serta memasukkan penyelenggaraan praktik klinis pendidikan Ners di dalam Hospital By Law atau Clinic By Law.
\end{abstract}

Kata Kunci: Perlindungan hukum, Mahasiswa Pendidikan Ners, Institusi Kesehatan

\section{ABSTRACT}

Introduction: The phase of nursing profession of Indonesian nursing education system (after Bachaleurate) are fully carried out at the health care institutions, yet there is no teaching hospital (RSP), Nursing Association and Government Regulation that protect nursing students which regard to their responsibilities and rights. The purpose of this study to determine setting of legal protection against nursing students profession in implementing clinical. Method: This research utilized normative juridical approach, legal research conducted by examining the data or material library is secondary data in the form of primary legal materials, secondary law or tertiary legal materials. Result: The result of this study indicate that legal protection for profession nursing students in implementing clinical practice is unclear and not concrete. Discussion: It is recomended the government make clear regulations as legal protection for profesion nursing student in implementing clinical practice, education agency nursing prepare students optimally, Health Institutions prepare for mentor optimally, and include the clinical practice in the Hospital by Law or clinic by Law.

Keywords: Legal Protection, Profession Nursing Student, Health Institutions

JURNAL

SKOLASTIK KEPERAWATAN

Vol. 2, No.2

Juli - Desember 2016 


\section{PENDAHULUAN}

Perawat sebagai bagian dari tenaga kesehatan harus menempuh pendidikan untuk dapat melayani di masyarakat sebagaimana ditegaskan dalam UndangUndang Republik Indonesia Nomor 36 Tahun 2009, tentang Kesehatan. Pada Pasal 1 ayat (6) Tenaga kesehatan adalah setiap orang yang mengabdikan diri dalam bidang kesehatan serta memiliki pengetahuan dan/atau keterampilan melalui pendidikan kesehatan yang untuk jenis tertentu memerlukan kewenangan untuk melakukan upaya kesehatan.

Dalam Undang-undang Pendidikan Tinggi Pasal 24 dijelaskan bahwa, program profesi merupakan pendidikan keahlian khusus yang diperuntukkan bagi lulusan program sarjana atau sederajat untuk mengembangkan bakat dan kemampuan memperoleh kecakapan yang diperlukan dalam dunia kerja.

Menurut Florence Nightingale, yang dikutip Blais, Hayes, Kozier, Erb (2012) pendidikan keperawatan harus meliputi teori dan praktek, keperawatan telah berkembang untuk memasukkan kedua dimensi ini. Disiplin pendidikan perawat dibagi menjadi disiplin akademik dan disiplin profesional, disiplin profesional diarahkan ke tujuan praktik klinis dengan menggunakan teori deskriptif dan preskriptif dan menambahkan penelitian klinis sejalan dengan penelitian dasar dan terapan. Menurut organisasi Persatuan Perawat Nasional Indonesia atau PPNI (2008) disiplin Profesional dalam pendidikan perawat disebut pendidikan profesi ners (nurse) yaitu (sarjana + Ners), yang mana lulusannya mendapat sebutan Ners, dan sebutan gelarnya (Ns).

Program pendidikan Ners disebut juga sebagai proses pembelajaran klinik. Istilah ini muncul terkait dengan pelaksanaan pendidikan profesi yang sepenuhnya dilaksanakan di lahan praktik seperti rumah sakit (rumah sakit tipe A, tipe B maupun tipe C), puskesmas, klinik bersalin, panti wherda, keluarga serta masyarakat atau komunitas tempat peserta didik belajar menerapkan teori tindakan ke dalam masalah klinis yang nyata. Dalam melaksanakan praktek klinis mahasiswa dibimbing oleh pembimbing klinik yang sering disebut instruktur klinik atau preceptor yang disediakan oleh institusi kesehatan dan dibantu pembimbing klinik dari pendidikan yang berperan sebagai perancang dan pengembang model pembelajaran (Tim KBK AIPNI, 2010).

Penelitian dari Haryatiningsih Purwandari (2012) menemukan bahwa keberhasilan pembelajaran klinik dipengaruhi oleh beberapa faktor seperti lingkungan belajar klinik, ketidaksesuaian antara teori dan praktik, dan kemampuan mahasiswa menghadapi tekanan di tempat praktek. Hal tersebut dapat berpotensi menyebabkan terjadinya kesalahan-kesalahan dalam melakukan prosedur pelayanan dasar.

Kelalaian juga dapat terjadi karena pembimbing lapangan atau perawat senior yang bertugas kurang fokus dalam membimbing seperti yang kasus yaang terjadi di Rumah Sakit Umum Daerah L Sumut Mahasiswa perawat salah memberikan obat Naritidin 50 mg, Naufalgis $45 \mathrm{mg}$ atas perintah perawat bakti berinisial CM kepada pasien bayi perempuan yang baru berumur 34 hari saat menjalani perawatan. Saat itu ibu pasien bertanya berulang-ulang kepada perawat tersebut, apa benar ini obat buat anaknya. Kala itu, perawat yang melakukan praktek itu membenarkan bahwa itu obat buat anaknya. Lalu obat suntik dimasukkan ke cairan infus pasien. Akibatnya bayi mengalami muntahmuntah, kejang dan perut kembung serta badan lemas. Kemudian bayi mendapat perawatan dari dokter sehingga bayi tersebut berangsur baik, sementara perawat senior yang mendampingi mahasiswa perawat yang praktek tidak mau disalahkan, mahasiswa dipulangkan ke kampusnya dan akan diurus oleh kampus tempat mahasiswa tersebut menuntut ilmu.

Apabila kasus di atas dibawa ke ranah hukum bagaimana perlindungan terhadap 
mahasiswa tersebut, siapa yang harus digugat, bila keluarga pasien atau pasien menganggap kejadian tersebut adalah murni kesalahan mahasiswa perawat yang sedang praktik. Dalam Undang-Undang Kesehatan Pasal 27 Ayat (1) dijelaskan bahwa tenaga kesehatan berhak mendapatkan imbalan dan perlindungan hukum dalam melaksanakan tugas sesuai dengan profesinya.

Pasal di atas memberi jaminan hukum terhadap tenaga kesehatan, tetapi tidak berlaku terhadap mahasiswa profesi keperawatan karena masih dalam tahap pendidikan untuk mendapatkan sertifikat kompetensi untuk memperoleh ijazah ners dan persyaratan untuk memperoleh Surat Tanda Registrasi (STR). Setelah memiliki STR seorang perawat dapat memilki kewenangan untuk melakasanakan praktik keperawatan.

Menurut Priharjo (2008) Untuk mengetahui hak dan kewajiban peserta didik saat berpraktik semestinya ada kebijakan yang berisi tanggung jawab mahasiswa keperawatan dalam praktik sehingga mahasiswa, pasien, institusi pelayanan dan pendidikan merasa dilindungi secara hukum dan mengetahui apa yang harus dilakukan untuk menghindari kelalaian. Selanjutnya Sutoto (2012) dalam Rapat Tahunan ke XI AIPNI (Asosiasi Institusi Pendidikan Ners di Indonesia) menjelaskan bahwa wahana praktik seperti rumah sakit belum memiliki standar administrasi dan manajemen pengelolaan praktik mahasiswa, sehingga hubungan tak didukung Perjanjian Kerjasama (PKS) yg menjamin proses pendidikan keperawatan berkualitas. Belum adanya uraian tugas, tanggungjawab, wewenang, dan masa tugas ditetapkan bersama instansi rumah sakit dan instansi pendidikan.

Undang-Undang Republik Indonesia Nomor 38 Tahun 2014 tentang Keperawatan belum mengakomodasi tentang perlindungan hukum terhadap mahasiswa keperawatan program pendidikan Ners dalam melaksanakan praktik di institusi kesehatan. Maka dari itu, permasalahan yang akan diuraikan dalam tulisan ini adalah: Bagaimana peraturan perundang -undangan mengatur pelaksanaan praktik klinis bagi mahasiswa keperawatan Program pendidikan Ners di institusi kesehatan? Bagaimana implementasi perlindungan hukum terhadap mahasiswa keperawatan Program Pendidikan Ners dalam melaksanakan praktik klinis di institusi kesehatan?

\section{BAHAN DAN METODE}

Penelitian ini menggunakan metode pendekatan yuridis normatif. Menurut Soekamto (2002) Penelitian yuridis normatif yaitu penelitian hukum yang dilakukan dengan cara meneliti data atau bahan perpustakaan yang merupakan data sekunder berupa bahan hukum primer, bahan hukum sekunder maupun bahan hukum tersier. Soerjono Soekanto dan Sri Mamudji (1997) menambahkan bahwa: pendekatan penelitian hukum normatif dilakukan dengan penelitian inventarisasi hukum positif, penelitian terhadap asas-asas hukum, sistematika hukum, taraf sinkronisasi vertikal dan horizontal dan sejarah hukum. Penelitian jenis ini seringkali dikonsepsikan sebagai apa yang tertulis dalam peraturan perundang-undangan (law in book) (Aminudin dan Asikin, 2006).

Penelitian yang dilakukan bersifat deskriptif analitis. Menurut Songgono (2012) deskriftif bertujuan memaparkan data hasil pengamatan tanpa pengujian hipotesis hipotesis. Dalam memahami serta memberi arti terhadap fenomena yang kompleks harus menggunakan prinsip analisis yang logis. Fakta yang mendukung tidaklah dibiarkan sebagaimana adanya atau hanya dibuat deskripsinya saja, akan tetapi, harus dicari sebab akibat dengan menggunakan analisis yang tajam (Sunggono, 2012).

Dalam penelitian ini, yang dipergunakan adalah data-data sekunder dari bahanbahan berupa: 
a) Bahan Hukum Primer

1. Undang-Undang Dasar Republik Indonesia Tahun 1945.

2. Undang-Undang Nomor 20 Tahun 2003 Tentang Sistem Pendidikan Nasional,

3. Undang-Undang Republik Indonesia Nomor 44 tahun 2009 Tentang Rumah Sakit.

4. Undang-Undang Republik Indonesia Nomor 12 Tahun 2012 Tentang Pendidikan Tinggi.

5. Undang-Undang Republik Indonesia Nomor 36 Tahun 2014 tentang Tenaga Kesehatan.

6. Surat Keputusan Menteri Pendidikan Nasional RI Nomor 232 tahun 2000 tentang Pedoman Penyusunan Pendidikan Tinggi dan Penilaian Hasil Belajar.

b) Bahan Hukum sekunder

Bahan Hukum sekunder adalah bahan-bahan yang menunjang bahan hukum primer, antara lain literatur-literatu, artikel, publikasipublikasi, tesis yang mengandung bahan-bahan hukum positif

c) Bahan Hukum Tersier Merupakan bahan hukum penunjang yang dapat memberi petunjuk dan penjelasan terhadap bahan hukum primer, dan sekunder, seperti kamus umum, kamus hukum, majalah, koran dan jurnal ilmiah, serta bahanbahan diluar bidang hukum yang relevan dengan penelitian ini.

Dalam penelitian ini, untuk mendapatkan data yang lebih akurat maka digunakan pengambilan data yaitu kepustakaan (library research). Data yang diperoleh dalam penelitian ini dianalisis secara kualitatif yaitu dengan menggunakan data sekunder yang diperoleh dari studi kepustakaan, dengan mengadakan sistematisasi bahan-bahan hukum tertulis. Yuridis normatif kualitatif adalah cara menganalisis data dengan jalan menafsirkan dan mengkonstruksikan pernyataan yang terdapat dalam dokumen dan perundang-undangan. Menurut Soekamto (2002) Normatif karena bertolak dari penelitian peraturanperaturan yang ada sebagai norma hukum positif, sedangkan kualitatif berarti analisis data yang bertitik tolak pada usaha penemuan.

\section{HASIL}

Dari inventarisasi hukum positif di negara Indonesia yang berkaitan dengan perawat, kemudian dianalisis maka hasil yang diperoleh belum ada hukum yang memberikan perlindungan bagi mahasiswa pendidikan Ners dalam melaksanakan praktik klinis di institusi pelayanan kesehatan. Pendidikan profesi Ners mirip dengan pendidikan profesi kedokteran. Sistem pendidikan profesi ners adalah magang (internship- intern/presptee) dan sistem bimbingan dikenal dengan istilah preceptorship (preseptor). Pendidikan Kedokteran telah memiliki undang- undang pendidikan kedokteran yang berfungsi sebagai perlindungan hukum bagi mahasiswa Fakultas Kedokteran dan Kedokteran Gigi dalam proses belajarmengajar di bangku kuliah maupun di Rumah Sakit Pendidikan dan Wahana Pendidikan Kedokteran yang menjelaskan hak dan kewajiban mahasiswa kedokteran umum dan kedokteran gigi yang tertuang dalam Undang-Undang Republik Indonesia Nomor 20 Tahun 2013 tentang Pendidikan Kedokteran.

Melihat hasil observasi lapangan belum ada Rumah Sakit Pendidikan (RSP) Keperawatan dan Peraturan Pemerintah yang mengatur tentang perlindungan kepada mahasiswa profesi ners termasuk hak dan kewajiban mahasiswa profesi ners belum ada. Saat ini yang ada adalah Rumah sakit 
Pendidikan Kedokteran, pendidikan kedokteran lanjutan.

\section{PEMBAHASAN}

\section{Pengaturan Pelaksanaan Praktik Klinis Mahasiswa Keperawatan Program Pendidikan Ners di Institusi Kesehatan.}

Tujuan pendidikan Ners sesuai dengan dengan Keputusan Menteri Pendidikan Nasional Nomor 232 Tahun 2000 tentang Pedoman Penyusunan Kurikulum Pendidikan Tinggi dan Penilaian Hasil Belajar Mahasiswa, Pasal 2 Ayat (2) menjelaskan bahwa pendidikan profesional bertujuan menyiapkan peserta didik menjadi anggota masyarakat yang memiliki kemampuan profesional dalam menerapkan, mengembangkan, dan menyebarluaskan teknologi dan/atau kesenian serta mengupayakan penggunaanya untuk meningkatkan taraf kehidupan masyarakat dan memperkaya kebudayaan nasional.

Program pendidikan Ners merupakan lanjutan tahap akademik setelah pendidikan sarjana keperawatan dengan beban studi tiga puluh enam (36) SKS yang di tempuh dalam 2 (dua) sampai 3(tiga) semester, mengacu kepada Surat

Keputusan Menteri Pendidikan Nasional Republik Indonesia Nomor 045 tahun 2002 tentang kurikulum inti pendidikan tinggi. Kurikulum institusi pendidikan tahap profesi terdiri dari $60 \%$ kurikulum inti (22 SKS) dan 40\% kurikulum yang mencirikan institusi (14 SKS).

Dalam UU Keperawatan Bab III Pasal $5 \mathrm{~s} / \mathrm{d}$ Pasal 16 dijelaskan tentang pendidikan tinggi keperawatan dan fasilitas pelayanan kesehatan sebagai wahana pendidikan (tempat sebagai lahan praktik ). Seiring dengan pertambahan populasi dan permasalahan kesehatan yang lebih kompleks menuntut kebutuhan akan tenaga kesehatan bertambah sehingga memicu banyaknya sekolah perawat yang dibuka. Pertumbuhan sekolah-sekolah perawat tidak diimbangi dengan pertambahan fasilitas pelayanan kesehatan sehingga dalam satu rumah sakit digunakan oleh banyak institusi keperawatan sebagai lahan praktik. Hal ini akan mempengaruhi mutu lulusan perawat yang dihasilkan. Penulis merasa perlu adanya peraturan untuk mengatur jumlah institusi pendidikan perawat yang berpraktik pada satu rumah sakit atau disesuaikan dengan tipe rumah sakit.

Pendidikan profesi Ners mirip dengan pendidikan profesi kedokteran. Sistem pendidikan profesi ners adalah magang (internship- intern/presptee) dan sistem bimbingan dikenal dengan istilah preceptorship (preseptor). Pendidikan Kedokteran telah memiliki undang- undang pendidikan kedokteran yang berfungsi sebagai perlindungan hukum bagi mahasiswa Fakultas Kedokteran dan Kedokteran Gigi dalam proses belajarmengajar di bangku kuliah maupun di Rumah Sakit Pendidikan dan Wahana Pendidikan Kedokteran yang menjelaskan hak dan kewajiban mahasiswa kedokteran umum dan kedokteran gigi yang tertuang dalam Undang-Undang Republik Indonesia Nomor 20 Tahun 2013 tentang Pendidikan Kedokteran.

Melihat hasil observasi lapangan belum ada Rumah Sakit Pendidikan (RSP) Keperawatan dan Peraturan Pemerintah yang mengatur tentang perlindungan kepada mahasiswa profesi ners termasuk hak dan kewajiban mahasiswa profesi ners belum ada. Saat ini yang ada adalah Rumah sakit Pendidikan Kedokteran, pendidikan kedokteran lanjutan. Defenisi Rumah Sakit sebagai lembaga yang diberikan hak dan kewajiban dalam pelayanan kesehatan menurut (Wolper dan Pena) yang dikutip oleh Azrul Azwar (1996) Rumah sakit adalah tempat dimana orang sakit mencari dan menerima pelayanan kedokteran, pendidikan klinik untuk mahasiswa kedokteran, perawat dan berbagai tenaga profesi kesehatan lainnya. RSP Keperawatan adalah tempat mengembangkan pemahaman pengalaman belajar klinik dan sosialisasi profesionalisme 
perawat serta sebagai tempat penumbuhan dan pembinaan kemampuan dan sikap profesional. Oleh sebab itu RSP Keperawatan mutlak adanya. Organisasi PPNI perlu upaya agar ada peraturan pemerintah (PP) untuk RSP Keperawatan.

Dalam UU Keperawatan Pasal 14 yang berbunyi menjelaskan kriteria dosen atau pembimbing di lahan praktik keperawatan. Selanjutnya Peraturan Pemerintah Nomor 19 Tahun 2005 tentang Standar Nasional Pendidikan, kriteria seorang pembimbing klinik/preseptor sebagai berikut:

a. Minimal seorang ners tercatat (memiliki STR dan memiliki lisensi (SIK/SIP) yang berpengalaman klinik minimal 5 tahun

b. memiliki sertifikat kompetensi sesuai keahlian di bidangnya.

c. Telah berpengalaman minimal dua (2) tahun berturut-turut di empatnya bekerja di unit tempat perawat menjadi preseptor/mentor sehingga dapat membimbing peserta didik dengan baik.

d. Merupakan model peran ners yang baik dan layak dicontoh karena sikap, perilaku, kemampuan profesionalismenya di atas rata-rata.

e. Telah mengikuti pelatihan pendidik klinik

f. Dapat mendukung peserta didik, dalam pencapaian tujuan, perencanaan, kegiatan dan cara mengevaluasi.

Melihat hasil observasi di lapangan rasio preseptor dengan peserta didik tidak sesuai karena tidak semua perawat yang bekerja di institusi kesehatan bisa menjadi seorang preseptor karena saat ini belum banyak perawat yang memenuhi kriteria preseptor. Biasanya diutamakan perawat senior yang bekerja di tatanan layanan dan ditetapkan sebagai preseptor oleh direktur institusi kesehatan.

Institusi pendidikan keperawatan yang tidak memiliki fasilitas kesehatan sebagai wahana pendidikan akan membuat perjanjian kerjasama dengan institusi kesehatan yang memenuhi kriteria yang dibutuhkan. Dengan adanya perjanjian kerjasama menyebabkan adanya suatu hubungan hukum antara institusi kesehatan dan institusi pendidikan.

Dari pengamatan penulis hubungan kerjasama yang di jalin sering tidak ada bakordik antara institusi pendidikan dengan institusi kesehatan. Ada rumah sakit yang belum memilki uraian tugas tertulis peserta didik dan kebijakan yang mengatur batas kewenagan yang dapat dilakukan peserta didik. Ada institusi pendidikan tidak menjelaskan kompetensi yang dimiliki dan kompetensi yang di harapkan selama proses pendidikan, sehingga kondisi ini dapat memicu terjadinya kesalahan dari mahasiswa yang sedang berpraktik.

\section{Peraturan Perundangan Yang Memberi Perlindungan Terhadap Mahasiswa Program Profesi Dalam Melaksanakan Praktik Klinis.}

Menurut Philipus Hadjon (1987) perlindungan hukum bagi rakyat atau seseorang ada dua macam perlindungan, yaitu perlindungan hukum Preventif dan perlindungan hukum represif, pada perlindungan preventif. Artinya perlindungan preventif mencegah terjadinya sengketa, sedangkan sebaliknya perlindungan represif, bertujuan untuk menyelesaikan sengketa. Menurut Fred Almen dalam Hendrik (2013) fungsi hukum secara umum adalah kepastian hukum dan perlindungan hukum.

\section{a. Undang-undang Nomor 36 Tahun 2009 tentang Kesehatan}

Secara yuridis perlindungan hukum dalam tingkat yang paling tinggi secara operasional setelah UndangUndang Dasar 1945 adalah Undang - Undang No. 36 tahun 2009 tentang Kesehatan.

Perlindungan terhadap Tenaga kesehatan terdapat pada bab $\mathrm{V}$ tentang sumber daya bidang kesehatan yang terdapat dalam 
Pasal 27 Ayat (1) Tenaga kesehatan berhak mendapatkan imbalan dan perlindungan hukum dalam melaksanakan tugas sesuai dengan profesinya. Menurut penulis perlu adanya peraturan yang dapat memberi perlindungan terhadap pendidikan profesi perawat dan tenaga kesehatan lain yang sedang melaksanakan praktik klinis.

b. Undang-Undang Nomor 44 Tahun 2009 Tentang Rumah Sakit

Perlindungan dalam UU Rumah Sakit terhadap profesi ners terdapat Pada Pasal 3 butir (b) dan butir (d) fungsi rumah sakit untuk memberikan perlindungan dan kepastian hukum kepada pasien, masyarakat, lingkungan rumah sakit dan sumber daya manusia di rumah sakit. Penjelasan Pasal 3 pada huruf (d) yang dimaksud dengan sumber daya di rumah sakit adalah semua tenaga yang bekerja di rumah sakit baik tenaga kesehatan, termasuk perawat dan tenaga non kesehatan, dan termasuk juga di dalamnya mahasiswa profesi ners yang sedang menjalankan praktik klinis.

Soerjono Soekanto dan Herkutanto (1987: 129) menjelaskan lebih rinci fungsi rumah sakit melaksanakan usaha pendidikan dan latihan medis dan paramedis. Paramedis yang dimaksud adalah perawat vokasi dan profesi ners. Rumah sakit semestinya dapat memberikan perlindungan hukum secara preventif terhadap mahasiswa program profesi ners dalam melaksanakan praktik klinis dengan bertanggung jawab atas kesalahan yang dibuat oleh bawahannya (subordinate) yang di kenal dengan Vicarious liability.

Doktrin vicarious liability sejalan dengan Pasal 1367 KUHPerdata yang menjelaskan bahwa seorang tidak hanya bertanggung jawab atas kerugian yang disebabkan oleh perbuatannya sendiri, melainkan juga atas kerugian yang disebabkan perbuatan-perbuatan orang-orang yang menjadi tanggungannya, atau disebabkan oleh barang-barang yang berada dibawaah pengawasannya.

Rumah sakit dan institusi pendidikan terikat oleh adanya perjanjian kerjasama oleh sebab itu, bila terjadi kesalahan maupaun kelalaian, institusi kesehatan berupa rumah sakit atau fasilitas pelayanan kesehatan dapat memberikan perlindungan hukum secara preventif dan represif terhadap mahasiswa profesi ners dalam melaksanakan praktik klinins. Rumah sakit dapat tempat mahasiswa berpraktik dapat di tuntut menanggung akibat yang ditimbulkan (Priharj, 2008: 44).

c. Undang-Undang R I No. 38 Tahun 2014 tentang Keperawatan

Undang- undang Keperawatan tentang perlindungan hukum terhadap perawat terdapat pada Bab VII Bagian Kesatu Hak dan Kewajiban Perawat, pada Pasal 36 butir (a) menegaskan bahwa Perawat dalam melaksanakan Praktik Keperawatan berhak memperoleh pelindungan hukum sepanjang melaksanakan tugas sesuai dengan standar pelayanan, standar profesi, standar prosedur operasional, dan ketentuan Peraturan Perundangundangan.

Dalam pelaksanaan praktik klinis program profesi keperawatan, UU Keperawatan perlu menambahkan peraturan yang dapat melindungi mahasiswa dalam melakasanakan praktik klinis termasuk hak dan kewajiban mahasiswa seperti pendidikan kedokteran.

d. Undang-Undang No 36 Tahun 2014 Tentang Tenaga Kesehatan

Ketentuan yang terdapat di dalam Undang- undang Nomor 36 Tahun 2014 yang berkaitan dengan 
perlindungan hukum terhadap tenaga kesehatan terdapat pada Bab $X$ Perlindungan bagi tenaga kesehatan dan penerima pelayanan kesehatan yang terdapat dalam pasal 75 yang berbunyi, tenaga kesehatan dalam menjalankan praktik berhak mendapatkan perlindungan hukum sesuai dengan ketentuan Peraturan Perundangundangan.

Undang-undang tenaga kesehatan tidak memberikan perlindungan hukum terhadap mahasiswa program profesi ners karena belum memiliki STR sehingga belum dianggap sebagai tenaga kesehatan.

e. Peraturan Menteri Kesehatan No.148 Tahun 2010 tentang Izin dan Penyelenggaraan Praktik Perawat

Dalam Pasal 11 ditegaskan bahwa, dalam melaksanakan praktik perawat mempunyai hak; memperoleh perlindungan hukum dalam melaksanakan praktik keperawatan sesuai standar, memperoleh jaminan perlindungan terhadap resiko kerja yang berkaitan dengan tugasnya. Mahasiswa progaram profesi ners belum memiliki STR sehingga belum mendapat perlindungan dari Peraturan Menteri Kesehatan No.148 Tahun 2010 tentang Izin dan Penyelenggaraan Praktik Perawat.

\section{Perjanjian Kerjasama antara Institusi Pendidikan dan Institusi Kesehatan}

Perjanjian sah dan mengikat apabila memenuhi unsur-unsur dan syarat-syarat seperti yang ditetapkan oleh undangundang. Abdukadir Muhammad (2014: 299300) menjabarkan ketentuan Pasal 1320 KUHPerdata, bahwa setiap penjanjian selalu memiliki empat unsur sebagai berikut:

\section{a. Persetujuan Kehendak \\ Perjanjian Kerjasama antara Universitas Advent Indonesia(UNAl)}

dengan Rumah Sakit Jiwa Provinsi Jawa Barat dan Perjanjian kerjasama dengan Rumah sakit Advent Bandung terdapat unsur persetujuan kehendak, karena kedua belah pihak telah memenuhi sayarat, tidak karena terpaksa, adanya penipuan atau kekhilafan.

b. Kewenangan (Kecakapan)

Dalam hal ini penulis melihat bahwa kedua pihak sudah dewasa, tidak mengalami ganngguan kejiwaan sehingga telah memiliki unsur kewenangan.

c. Objek (Prestasi) Tertentu Untuk melaksanakan pendidikan/penelitian dan pengabdian masyarakat dengan mengikuti ketentuan yang berlaku di Rumah sakit Jiwa Provinsi Jawa Barat dan Rumah sakit Advent Bandung. Selama terikat dalam perjanjian Pihak kedua mempunyai kewajiban membayar institusional fee atas fasilitas yang digunakan dan bimbingan yang diberikan oleh pihak kesatu (institusi kesehatan) sesuai kesepakatan.

\section{d. Tujuan Perjanjian}

Tujuan perjanjian yang akan dicapai oleh pihak-pihak sifatnya harus halal. Pada pasal 1367 KUHPerdata menyebutkan sebagai berikut Seseorang harus memberikan pertanggung-jawaban tidak hanya atas kerugian yang ditimbulkan dan tindakannya sendiri, tapi juga atas kerugian yang ditimbulkan dari tindakan orang lain yang berada dibawah pengawasannya. Ada kalanya seorang dalam pergaulan hidup bermasyarakat menurut hukum berada di bawah pengawasan orang lain, seperti halnya seorang curandus dalam hal curatele di bawah pengawasan seorang curator, seorang murid sekolah di bawah pengawasan pengawsan seorang 
guru dalam lingkungan pelajaran yang diberikan. Dalam hal ini seorang pengawas dianggap mempunyai tugas untuk menjaga, jangan sampai seorang yang diawasi itu melakukan perbuatan melanggar hukum (Prodjodikoro, 2000)

Pembimbing klinik mempunyai tanggung jawab dalam melakukan supervisi terhadap mahasiswa profesi ners, dan kegagalan dalam melakukan tanggung jawab ini merupakan dasar terjadinya kelalaian, seperti pada kasus di RS L, seharusnya mahasiswa mendapat perlindungan dari institusi kesehatan tetapi yang terjadi adalah hanya menjadi tanggung jawab pihak kedua (institusi pendidikan). Karena dalam perjanjian kerjasama ditegaskan bahwa, pihak kedua bertanggung jawab atas segala kerugian yang timbul, dan menanggung segala biaya atas kecelakaan/ kematian dari pihak ketiga akibat kegiatan pendidikan /penilitian dan pengabdian masyarakat. Menurut penulis tujuan perjanjian tidak seimbang karena memberatkan pihak kedua. Perlu penataan kembali dalam membuat perjanjian kerjasama agar mahasiswa sebagai objek perjanjian mendapat perlindungan dari kedua belah pihak.

\section{SIMPULAN DAN SARAN}

\section{Simpulan}

1. Ada 2 (dua) peraturan perundangundangan yang menyinggung tentang pendidikan keperawatan baik vokasi maupun profesi tetapi belum memberikan perlindungan yang jelas dan kongkret bagi mahasiswa profesi ners dalam melaksanakan praktik klinis, yaitu Undang-Undang Nomor 44 Tahun 2009 tentang Rumah Sakit, Pasal 5 butir (c) menjelaskan salah satu fungsi rumah sakit adalah penyelenggaraan pendidikan dan pelatihan sumber daya manusia dalam rangka peningkatan kemampuan dalam pemberian pelayanan kesehatan, dan Undang-Undang Republik Indonesia No. 38 Tahun 2014 tentang Keperawatan, pada Bab III tentang pendidikan tinggi keperawatan, tetapi belum diatur mekanisme profesi pendidikan perawat di lahan praktik termasuk hak dan kewajiban mahasiswa.

2. Implementsi perlindungan bagi mahasiswa keperawatan program profesi dalam melaksanakan praktik klinis belum jelas karena belum ada aturan perundangan yang jelas tentang hak dan kewajiban mahasiswa program profesi ners dalam melaksanakan praktik klinis di institusi kesehatan. Perjanjian kerjasama antara institusi pendidikan dan institusi kesehatan tidak memberikan perlindungan.

\section{Saran-saran}

1. Kepada Pemerintah

a. Untuk mengoptimalkan pendidikan profesi keperawatan agar berbagai Peraturan Pemerintah (PP) yang ditegaskan dalam beberapa undang-undang, harus segera direalisir.

b. Peraturan Pemerintah mutlak untuk pembentukan Rumah Sakit

Pendidikan 
Keperawatan, dan mengatur jumlah ianstitusi pendidikan keperawatan yang melaksanakan praktik klinis di institusi kesehatan

2. Kepada Institusi Pendidikan, agar mempersiapkan mahasiswa secara optimal secara teori dan praktik di laboratorium sehingga meminimalisasi kesalahan.

3. Kepada Institusi Kesehatan,
a. Agar memasukkan penyelenggaraan praktik klinis profesi ners di dalam Hospital by Law atau Clinic by Law.
b. Diharapkan mengembangkan kemampuan pembimbing lapangan (preseptor) sesuai dengan standar.

\section{DAFTAR PUSTAKA}

Abdulkadr Muhammad, Hukum Perdata Indonesia, Citra Aditya Bakti, Bandung, 2014

Aminudin dan Zaenal Asikin, Pengantar Metode Penelitian Hukum, PT. Raja Grafindo Persada, Jakarta, 2006

Azrul Azwar, Pengantar Administrasi Kesehatan, Binarupa Aksara, Jakarta, 1996

Bambang Sunggono, Metode Penelitian Hukum, Rajawali Pers, Jakarta, 2012

Blais, K.K., Hayes J. S., Kozier, B., Erb G, Praktik Keperawatan Profesional Konsep \& Praktik, Jakarta, EGC, 2012

Draft Naskah Akademik Pendidikan Keperawatatan, PPNI, Jakarta, 2008

Philipus M.Hadjon, Perlindungan Hukum Bagi Rakyat Indonesia, Binacipta, Surabaya, 1987
Prodjodikoro, W Perbuatan Melanggar Hukum Dipandang Dari Sudut Hukum Perdata, CV Mandar Maju, Bandung, 2000

Hendrik, Etika Hukum Kesehatan, Jakarta, EGC, 2011

Robert Priharjo, Konsep dan Perspektif

Keperawatan Profesional, EGC, 2008

Soerjono Soekanto, Metode Penelitian

Hukum, UI Press, Jakarta, 2002

Soerjono Soekanto dan Herkutanto, Pengantar Hukum Kesehatan, Remadja Karya, Bandung,1987

Soerjono Soekanto dan Sri Mamudji, Penelitian Hukum Normatif, Rajawali Press, Jakarta,1997

TIM KBK AIPNI, Kurikulum Pendidikan Ners, AIPNI, Jakarta, 2010

\section{Sumber lain}

Sutoto, disampaikan dalam seminar Implikasi UU No. 12 Tahun 2012 Terhadap Pendidikan Keperawatan di Indonesia, Surabaya, 2 Desember 2012

Haryatiningsih Purwandari dkk, Permasalahan Mahasiswa Pada Penempatan Praktik Ners Pertamakali di stase Keperawatan Anak, Fakultas Keperawatan Onsoed,Purwokerto, 2011

http;//medanbisnisdaily.com/new/read/2013/ 06/66322/perawat_rsud_langsa_didu ga_malpraktek/ diakses 20 Maret 2014, pukul $20.00 \mathrm{WIB}$ 